\title{
UM ESTUDO SOBRE O PROCESSO DE OCUPAÇÃO DO PARQUE OESTE INDUSTRIAL A PARTIR DAS REPORTAGENS VEICULADAS NA IMPRENSA
}

\author{
A STUDY ON THE OCCUPANCY PROCESS OF THE INDUSTRIAL WEST PARK FROM THE \\ PRESS REPORTS
}

\author{
Carlos Felipe Lacerda Ramalho', Leila Maria Ferreira Salles²
}

RECEBIDO: 28/09/2017 | ACEITO: 25/09/2019

DOI: $10.5902 / 2317175829303$

\section{RESUMO}

Este trabalho apresenta uma análise a partir de um levantamento das notícias publicadas pelos jornais O Popular e Diário da Manhã, referentes à maior desocupação urbana de Goiás, ocorrida em 2004, na região do Parque Oeste Industrial de Goiânia, em uma grande área urbana particular. A ocupação, que se iniciou em 2004, chegou a abrigar 4 mil famílias e a sua desocupação, amplamente coberta pela mídia, foi realizada pela Polícia Militar de Goiás, com registros de violência. Após a desocupação, as famílias foram levadas para ginásios esportivos e depois para uma área provisória no Setor Grajaú (onde viviam em barracos de lona), até o assentamento definitivo no Residencial Real Conquista, construído para abrigá-las e que só ficou completo em 2014. O estudo busca saber se a imprensa goiana, financiada pelo poder estadual, poderia ser um espaço adequado para a expressão daqueles moradores provisoriamente ali instalados, bem como, qual foi o seu grau de influência no desfecho do caso. Este trabalho busca, assim, propor reflexões e diagnósticos sobre o processo de ocupação urbana e o acesso à moradia em Goiânia, visando contribuir para políticas públicas voltadas para a melhoria das condições de moradia da população. Seu tema central é a discussão do papel dos veículos de comunicação na construção da opinião pública e na garantia dos direitos sociais como a Moradia.

Palavras-chave: Ocupação Urbana; Parque Oeste Industrial de Goiânia; Residencial Real Conquista; Imprensa Goiana

1 Mestre em Desenvolvimento Regiona. Centro Universitario Alfa- UNIALFA

2 Professora do programa de Pos - Graduaçao em Educaçao, UNESP/RC e do Mestrado em Desenvolvimento Regional, UNIALFA 


\section{ABSTRACT}

This paper presents an analysis based on a survey of the news published by the newspapers O Popular and Diário da Manhã, referring to the largest urban eviction in Goiás, which occurred in 2004, in the region of Parque Oeste Industrial, in a large private urban area. The occupation, which began in 2004, housed 4,000 families and its eviction, largely covered by the media, was carried out by the Goiás Military Police, with records of violence. After the removal, families were taken to sports gyms and then to a temporary area in the Grajaú Sector (where they lived in canvas tents), until the permanent settlement in the Residencial Real Conquista, built to house them and that was only completed in 2014. The study seeks to find out if the state-funded Goiás Press could be an adequate space for the expression of those residents temporarily installed there as well as its degree of influence on the outcome of the case. Thus, this paper seeks to propose reflections and dianoses on the on the outcome of the case. Thus, this paper seeks to propose reflections and diagnoses on the urban occupation process and access to housing in Goiânia, aiming to contribute to the formulation of public policies aimed at improving the living conditions of the population. Its central theme is the discussion of the role of communication vehicles in the construction of public opinion and in the guarantee of social rights such as Housing.

KeyWord: Urban Occupation, Parque Oeste Industrial de Goiânia; Residencial Real Conquista; Goiana Press

\section{Introdução}

Uma grande área urbana particular localizada na região sudoeste de Goiânia, no bairro chamado Parque Oeste Industrial, estava sem utilização, desde a criação em 1957. Isso permitiu que, em 2004, famílias sem teto ocupassem a região e dessem o nome de "Sonho Real" ao local. Já no ano seguinte, eram cerca de 4 mil famílias, tornando-se a maior ocupação urbana já vista no estado. A sua desocupação, ocorrida no ano seguinte, resultou oficialmente em mortes, feridos e detenções.

Importante lembrar igualmente que, entregue à especulação imobiliária, o loteamento tinha na época da invasão uma dívida com o Poder Público de cerca de $\mathrm{R} \$ 2,5$ milhões, fruto de impostos atrasados. Mesmo assim representantes do segmento da construção civil, por meio do setor imobiliário fizeram fortes gestões, junto ao Poder Público, exigindo a reintegração de posse dessa região localizada nas proximidades de grandes condomínios verticais e, atualmente, vendida por meio de anúncios na mídia goianiense como uma das áreas mais promissoras.

A desocupação mobilizou todo o poder público estadual e também a Secretaria de Direitos Humanos da Presidência da República. Ainda assim, processo de desocupação pelo Poder Público (chamado Operação Triunfo) foi bastante violento, rápido e mobilizou a Polícia Militar e o Grupo de Operações Táticas Especiais (GATE). Oficialmente, houve duas mortes, catorze feridos, centenas de presos, sendo que, nos dias seguintes, os jornais locais já informavam a desocupação total do local. Após esse processo as famílias foram levadas para dois ginásios esportivos, onde faleceram três pessoas, em con- sequência das condições precárias dos locais. Em seguida elas foram alojadas em uma área provisória no Setor Grajaú (onde viviam em barracos de lona). Lá morreram mais oito adultos e nove bebês recém-nascidos ou em gestação, até o assentamento definitivo no Residencial Real Conquista, construído para abrigá-las e que só ficou completo em 2014 (SILVA, 2007, p.116).

O Residencial Real Conquista, que levou sete anos para ficar totalmente pronto, possui nove módulos e abriga atualmente 2.470 famílias que foram selecionadas para residir no local de acordo com critérios definidos pelo órgão estadual Agehab (Agência Goiana de Habitação). A construção do residencial ocorreu por meio de um arranjo entre governo de Goiás, com a participação da Agehab e da Saneago (Saneamento de Goiás S/A), do governo federal, tendo a Caixa Econômica Federal como o agente financeiro e a prefeitura de Goiânia. O último módulo do Residencial foi entregue no mês de maio de 2014, totalizando hoje uma população de 12 mil habitantes.

Este estudo tem, então, como objetivo investigar o processo de ocupação e desocupação das famílias do Parque Oeste Industrial. Para tanto, foi feito um mapeamento e análise de materiais jornalísticos que tratavam da ocupação/desocupação do loteamento nos dois maiores e mais importantes jornais impressos de Goiás: O Popular e Diário da Manhã entre os anos de 2004 a 2014. Buscamos cobrir todo o período de dez anos do conflito, ou seja, até a transferência das famílias para o assentamento Real Conquista.

Os dois jornais foram selecionados, pela sua grande importância regional (são os dois veículos diários com maior representatividade), visto que circulam em todo o estado e tem também uma longa história que caminha paralelamente com o desenvolvimento da capital sendo reconhecidos pela sociedade local como uma das principais fontes de informação regional. O Popular é o jornal local de maior circulação no estado de Goiás e um dos mais influentes do estado. Foi fundado por Jaime Câmara, Joaquim Câmara Filho e Vicente Rebouças Câmara, em 1938. Neste jornal, em média, pelo menos duas matérias eram publicadas a cada mês. Já o jornal Diário da Manhã, foi idealizado pelo jornalista Batista Custódio, em 1980. Este jornal não pertence a um conglomerado econômico maior, possuindo uma linha editorial mais voltado para as camadas populares e de caráter editorial mais alinhada ao poder constituído. Na década de 1980, o jornal chegou a ser considerado um dos principais do país, contando com a participação de jornalistas de renome nacional.

As matérias jornalísticas veiculadas nos dois jornais diários foram conseguidas junto aos CEDOC's, (Centro de Documentação) de cada veículo. No período de 2004 a 2012, foram publicadas oitenta e nove matérias jornalísticas sobre o tema Parque Oeste Industrial, sendo 65 no Jornal O Popular e 34 no Jornal Diário da Manhã. Os termos pesquisados nos Centros de Documentações dos Jornais foram: "Real Conquista" e "Parque Oeste Industrial". O material coletado foi organizado em categorias analíticas (unidades de dados segmentados e com algo comum) por meio de agrupamentos de elementos 
discursivos comuns (GIL 2010; BOGDAN, R., BIKLEN, 1994, BARDIN, 1977). Os temas básicos abordados nas matérias serviram como eixos norteadores da análise. As categorias de análise deste estudo ficaram assim constituídas: movimento e seus ocupantes; a posse e situação legal do terreno e o processo de ocupação e da desocupação.

\section{Sobre o Direito à Moradia}

É importante situar a questão do Direito à Moradia dentro do próprio contexto de desenvolvimento dos Movimentos Sociais Urbanos, do qual derivam outros como o movimento dos sem teto, na luta pela Cidadania como conjunto de direitos no país. Segundo Luca (2013), até a década de 1940, Cidadania no Brasil crescia por meio das leis e concessões do Estado, que definia quem poderia ou não ser considerado cidadão e não como resultado de conceitos universais e doutrinários. Assim, "nota-se que a Cidadania não figurava como resultado da luta política, antes dependia da benemerência do estado, que fazia concessões a determinados segmentos sociais" (LUCA, 2013, p. 486). Somente na década de 1960 , as formas de organização não atreladas às normas do Ministério do Trabalho começam a surgir como Ligas Camponesas, comissão de fábricas e outros grupos que lutam pela ampliação dos direitos.

Esse movimento alcança seu ápice em 1964, durante o governo João Goulart e é drasticamente interrompido com o período da Ditadura Militar. As centrais sindicais e camponesas foram proibidas, dirigentes sindicais foram presos e centenas de sindicatos e associações sofreram intervenção. Para Luca (2013), voltou ainda mais forte um modelo de cidadania lastreado na "benevolência" e paternalismo estatal, mas sempre em consonância com os anseios do capital internacional. Só a partir do final da década de 1970, com as greves no $A B C$ paulista, essa situação começa a desgastar e culminar com a promulgação da Constituição de 1988, cujo texto é inegavelmente uma apologia à Cidadania. Porém a realidade nacional ainda caminha oposta aos preceitos da Carta Magna.

Estudo bastante criterioso e aprofundado sobre o tema foi realizado por Carvalho (2011), que traça todo o caminho realizado pela construção desse direito no Brasil desde a época do Império, passando pela República, pela Ditadura Militar até os dias atuais, após a redemocratização. Segundo o autor, no Brasil, décadas passadas desde o fim da ditadura, problemas centrais, como a violência urbana, o desemprego, o analfabetismo, a má qualidade da educação, a oferta inadequada dos serviços e as grandes desigualdades sociais e econômicas ou continuam sem solução ou se agravam e quando melhoram, em ritmo muito lento. Isso porque dependem de uma eficiente máquina administrativa contra a crise dos estados nacionais.

Carvalho (2011) define o conceito de Cidadania e evidencia como ele nasce da consolidação de três direitos fundamentais: civis (fundamentais à vida como a liberdade, propriedade, igualdade perante a lei) que garante relações civilizadas entre as pessoas, políticos (basicamente a participação do cidadão no governo da sociedade, com o voto) e sociais (que garantem a participação na riqueza coletiva tais como a saúde, trabalho, educação, salário justo e o direito à moradia). $O$ autor salienta que os direitos civis se baseiam na existência de uma Justiça acessível a todos e eficiente, garantindo a sobrevivência da sociedade civil. Já os direitos políticos decorrem da capacidade de votar e ser votado, de organização partidária. Obrigatoriamente para existirem os direitos políticos, também devem ser estar satisfeitas as condições para os direitos civis. Já os direitos sociais dizem respeito ao direito à educação, ao trabalho, à saúde, aposentadoria e também o direito à moradia. Segundo Carvalho (2011) a garantia desses direitos depende da eficiência da máquina estatal em garantir a chamada justiça social, pois "permitem às sociedades politicamente organizadas reduzir os excessos de desigualdade produzidos pelo capitalismo e garantir um mínimo de bem-estar social para todos" (CARVALHO, 2011, p. 10).

$\mathrm{O}$ autor também apresenta dados sobre a desigualdade que impactam na consolidação da Cidadania 1997, a taxa de analfabetismo no Sudeste era de $8,6 \%$; no Nordeste, de $29,4 \%$. O analfabetismo funcional no Sudeste era de $24,5 \%$; no Nordeste era de $50 \%$, e no Nordeste rural, de $72 \%$; a mortalidade infantil era de $25 \%$ no Sudeste em 1997, de $59 \%$ no Nordeste e, assim por diante. O mesmo se dá com relação a cor. O analfabetismo em 1997 era de 9,0\% entre os brancos e de $22 \%$ entre negros e pardos; os brancos tinham 6,3 anos de escolaridade; os negros e pardos, 4,3; entre os brancos $33,6 \%$ ganhavam até um salário mínimo; entre os negros, $58 \%$ estavam nessa situação, e $61,5 \%$ entre os pardos; a renda média dos brancos era de 4,9 salários mínimos; a dos negros, 2,4, e a dos pardos, 2,2. Esses exemplos poderiam ser multiplicados sem dificuldade (CARVALHO, 2011, p. 208)

Neste contexto, o Direito à Moradia é garantido no Artigo $6^{\circ}$ da Constituição Federal', mas ainda caminha devagar no país (a exemplo de outros direitos sociais), mesmo com indicadores melhores nos últimos anos. Segundo dados do Ipea (Instituto de Pesquisa Econômica Aplicada), entre 2007 e 2012, houve uma redução de $6,27 \%$ no déficit habitacional no país, que passou de 5,59 para 5,24 milhões de moradias ${ }^{4}$. Essa queda ocorreu ao mesmo tempo em que houve aumento de $12,6 \%$ no total de domicílios, de 55,918 milhões para 62,996 milhões. Assim, em termos relativos, o déficit caiu de $10 \%$ do total de domicílios para $8,53 \%$ no período. Porém, de acordo com o estudo, o déficit habitacional brasileiro, mesmo diminuindo em todas as faixas de renda, ficou ainda mais concentrado entre as famílias que ganham até três salários, ou R\$ 3 Art. $6^{\circ}$ São direitos sociais a educacăăo, a saúde, a a alimentação, o trabalho, a moradia, o lazer, a seguran-
ça, a previdência social, a proteção à maternidade e à infância, a assistência aos desamparados, na forma

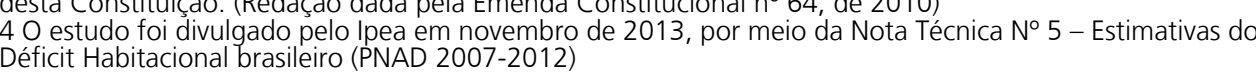


2.034 por mês. O conceito de déficit é definido a partir da avaliação de quatro componentes: moradias precárias (domicílios precários ou rústicos), coabitação familiar (mais de uma família no cômodo), o peso do aluguel (se for mais que $30 \%$ é considerado excessivo) na renda da família, além do adensamento excessivo em domicílios, ou seja, que ocorre nos locais que possuem mais de três habitantes por cômodo locado e que sirva como dormitório.

Ao analisarmos os dados constatamos que, diferentemente do restante do país, o déficit aumentou em todos os estados da região Centro Oeste, com exceção do Mato Grosso do Sul. Houve um aumento no déficit de 44.082 unidades habitacionais no Centro Oeste, crescimento relativo de $11,3 \%$. 0 estado com maior contribuição para esse resultado foi o Distrito Federal, com aumento de $20,02 \%$. Só o Mato Grosso do Sul apresentou queda de $10,07 \%$. Já em Goiás o déficit aumentou em mais 20 mil unidades habitacionais acumulando um déficit total de 161,29 moradias.

Com base nessa suposição buscamos os dados de imigração junto à SEGPLAN (Secretaria de Gestão e Planejamento do Estado de Goiás). O estudo mais recente ${ }^{5}$ mostra que o estado de Goiás possui $43 \%$ de toda a população do Centro Oeste e representa hoje 3,15\% da população brasileira (em 1991 era $2,74 \%$ ). Destaca ainda que a taxa de crescimento geométrico do estado continua, há duas décadas, bem superior à taxa brasileira, sendo que na década de 2000 a 2010 alcançou $1,84 \%$ ante $1,17 \%$ da taxa nacional, fato que fez com que Goiás ganhasse um milhão de habitantes no intervalo de apenas uma década.

Estes dados mostram o paradoxo desafiador para a elaboração, execução e controle de agendas e políticas públicas integradas (em um país com dimensões continentais como o Brasil) que objetivam a redução o mais uniforme possível das desigualdades regionais, como é esse caso específico do Direito à Moradia. Constatamos que mesmo com a melhoria considerável do acesso ao credito e de programas habitacionais, nos últimos anos, outras variáveis ainda continuam influenciando a imigração para o estado de Goiás. Carlos (2013) aponta a existência de uma verdadeira crise no país: só em São Paulo, a maio cidade da América Latina, cerca de 3 milhões de pessoas moram em cortiços e 1,5 milhões em favelas.

Segundo Carlos (2013), a predominância da propriedade privada da terra, que define as formas de acesso aos serviços (moradia incluída) produz um modelo de cidade que atende aos anseios do capital e não aos do maior conjunto da sociedade. Esses interesses contraditórios levam a um inevitáve conflito entre o capital, baseado no lucro, e a sociedade, que anseia por meIhores condições de vida. Para ela, somente a superação dessa ordem poderá acarretar na construção de uma cidade mais democrática e cidadã:

O direito à cidade, para Lefebvre, "manifesta-se como forma superior dos direitos: direito à liberdade, à individualização na 5 Dinâmica Populacional do Estado de Goiás - uma análise do Censo 2010 do IBGE, publicado em dezem-
bro de 2011 . socialização, ao habitat e à habitação. O direito à obra (a ativida-
de participante) e o direito à apropriação (bem distinto da propriedade) se imbricam dentro do direito à cidade. Nesse sentido, priedade) se imbricam dentro do direito a cidade. Nesse sentido, acabar-se-la com a separação cotidianidade-lazer, vida cotidiatrabalho produtivo, da obra e do lazer. A cidade seria a obra perpétua de seus habitantes, o que contraria a ideia de receptáculo passivo da produção e das políticas de planejamento (CARLOS, 2013, p. 33).

Conectado a essa realidade nacional, o estado de Goiás começa a sofrer os problemas da urbanização acelerada com a construção da nova capital. Porém, podemos citar o movimento de Trombas e Formoso como um dos mais importantes do estado no século passado. Segundo Oliveira (2005, p. 154), a vitoriosa revolta camponesa, em resposta às práticas violentas contra os posseiros, ocorrida em dois municípios do Norte Goiano, em 1951, foi marcante. Seu líder, José Porfírio, inclusive, consegue se eleger deputado estadual e apenas em 1964, com advento da ditadura militar, é que o movimento sai derrotado. Mas chegou a tal ponto de organização que forma um governo paralelo, constituído pelos Conselhos de Córregos e a Associação de Lavradores.

Oliveira (2005) mostra, porém, que avanços como esses que ocorriam em todo o país e iniciados nos anos 1950 e 1960, incomodaram as elites nacionais. Forja-se um pacto que destitui o presidente eleito, "João Goulart, e instala a ditadura militar. Por ela, os interesses da elite brasileira se cumpriram, a partir da elaboração de uma política econômica que favorecia o monopólio e a concentração" (OLIVEIRA, 2005, p. 147). Para o autor, este fato levou a uma intensa articulação e sinergia entre os poderes nacionais e locais, e os recursos sempre favoreciam os detentores do capital financeiro. No caso especifico de Goiás, essa política, segundo o autor, aumentou o êxodo rural ao fortalecer a estrutura fundiária existente. A capital do estado incrementou a sua população na década de 1960 em quase $154 \%$.

Carlos (2013) destaca que a emergência dos movimentos sociais urbanos no país coloca em xeque as contradições capitalistas no espaço urbano. Inicialmente gestados para combater a carência de necessidades básicas do dia a dia, seu crescimento ganha dimensão política mais ampla ao debater os direitos civis à moradia por meio de um movimento de luta. Segundo Oliveira, na década de 1970, ocorre a universalização dos problemas urbanos em Goiânia, fato gerador do rompimento de uma cidade concebida como harmônica e planejada. Surge a cidade "polifônica, em que os novos sujeitos entram em cena reivindicando seu espaço social" (OLIVEIRA, 2005. p. 150).

Moyses e Bernardes (2005, p. 176) mostram que as décadas de 1950 e 1970 impulsionam o desenvolvimento do Centro Oeste, "motivado pela intensa imigração atraída pela nova capital e por projetos de colonização que contribuíram para um rápido adensamento no interior do estado". Este fato exigiu do Poder Público da capital um rígido controle quanto ao parcelamento e ocupação do 
solo, que durou até 1950, segundo os autores. Porém, após esse período, o estado delega esse papel à iniciativa privada, que fica "livre da exigência de implantar infraestrutura. Esta se constitui a atividade de maior efervescência no fina desse ano, multiplicando de aproximadamente 12.000 para perto de 120.000 lotes o estoque imobiliário (MOYSES E BERNARDES, 2005, p. 177).

O movimento de luta pela moradia em Goiânia volta a ter expressão na década de 1980. Segundo Moraes (2003) a ausência de políticas públicas de mo radia voltadas para classes populares favoreceu a organização de trabalhadores sem teto, compostos por famílias que moram de favor ou de aluguel. Inicialmente organizando pequenas ocupações o movimento cresce e origina diversas ocupações na cidade, tendo como resposta a repressão estatal. Nesse contexto talvez uma das formas mais usuais de luta do movimento dos sem teto seja a invasão de áreas públicas. Curiosamente, no caso de Goiânia, este processo ocorre desde a fundação da cidade e envolve uma grande gama de bairros:

Os que foram chegando aos poucos, dispersamente, sozinhos ou com suas famílias, sem prévio contrato de trabalho, juntavam-se Essa regiấo ja residente à margem dirella do Corrego Botafogo. Essa regiáo ia se adensando à medida que novas moradias eram banístico de Goianni ss barrom-se outras regiões, posteriormo como Arião, Vila Nova invãós miliońrios, a postenplo da rua 115, no Setor Sul (área, iue era um parque linear, doado a tegião do , notor sul (área que era um parque líear, doado a Legia negociando os terrenos), Jardim Nova Esperanca, Vila Curitiba, Finsocial, Bairro da Vitoria e suas sete etapas, O Bairro São Carlos e o loteamento da Fazenda São somingos, Dom Fernando 1 e 2 Jardim Curitiba (MOYSES; BERNARDES, 2005, p. 192).

Em outro trabalho Oliveira e Moyses (2005) mostram que as camadas populares de Goiânia passam a ocupar espaços carentes de infraestrutura, como áreas próximas do centro e também loteamentos irregulares e clandestinos, na periferia. Este fato ocorre pela ação dos grupos econômicos do ramo imobiliário, ao definirem o local a ser ocupado devido à ausência de políticas públicas do estado, assentado num planejamento "municipal meramente urbano, que intervém sobre uma realidade consentida numa perspectiva política clientelística e assistencialista, bem como de contemplação dos interesses do capital imobiliário" (OLIVEIRA; MOYSES, 2005, p. 287)

Os pesquisadores exemplificam esse paradigma com o caso da ocupação da Região Noroeste da capital, que consistiu na politização e apadrinhamento das camadas populares, que já conseguiam se organizar e realizar ocupações exitosas, como o caso do Jardim Nova Esperança. Esta mobilização exigiu do Estado rediscutir a questão habitacional na cidade, mas a região ficou marcada pela degradação ambiental, pois não era área adequada ao parcelamento urbano já que possuía características tipicamente rurais, com grande reserva de matas.
É neste contexto de reivindicação de moradia e da impossibilidade de ela vir a se concretizar, pelo menos atualmente, no território brasileiro é que corre a ocupação/desocupação das famílias do Parque Oeste Industrial, que inclusive pela violência que permeou o processo, foi objeto de várias reportagens jornalísticas as quais analisamos neste estudo.

\section{A Ocupação e Desocupação do Parque Oeste Industrial nas reportagens veiculadas na imprensa.}

\subsection{0 movimento e seus ocupantes}

Um conjunto de reportagens veiculadas tanto no jornal O Popular como no Diário da Manhã procuraram caracterizar o movimento de ocupação e desocupação do Parque Oeste Industrial e seus ocupantes. Convém lembrar aqui o papel histórico do Estado no controle da informação e da imprensa no país, conforme evidenciam Lima e Borges (2008, p. 79) ao evidenciar que este controle se dá por abuso da autoridade (cassação de concessões, censura e empréstimos) e por meio de anúncios (públicos e privados). Segundo as autoras esse modelo ainda persiste e traz consigo sérias consequências para o resultado do trabalho jornalístico pois:

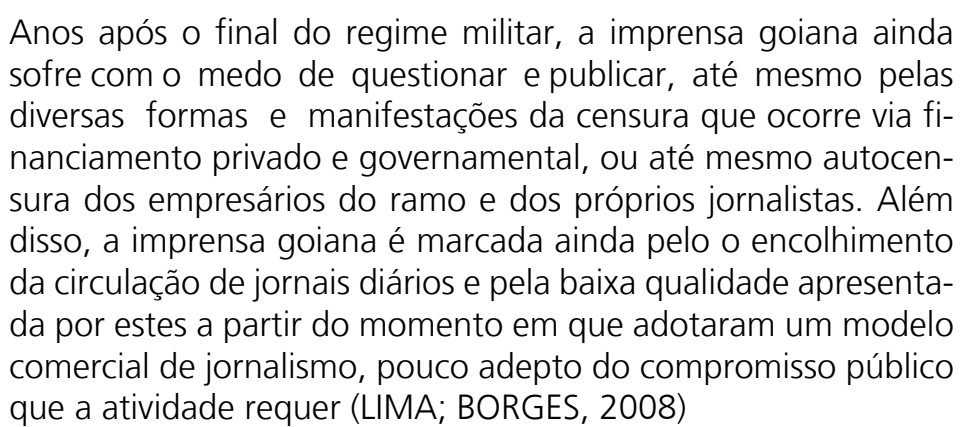

Anos após o final do regime militar, a imprensa goiana ainda sofre com o medo de questionar e publicar, até mesmo pelas nanciamento privado e governamental, ou até mesmo autocensura dos empresários do ramo e dos próprios jornalistas Além disso, a imprensa goiana é marcada ainda pelo o encolhimento da circulação de jornais diários e pela baixa qualidade apresentada por estes a partir do momento em que adotaram um modelo da por estes a partir do momento em que adotaram um modelo que a atividade requer (LIMA; BORGES, 2008)

A imprensa teve papel importante na narrativa do caso Parque Oeste Industrial ao relatar os acontecimentos do episódio pelo seu incontestável poder, como dizem McCombs e Shaws (2000), de influenciar a opinião do público, principalmente em situações de grande alcance, interesse e repercussão. Segundo Dias (2007, p. 120), "sempre acompanhados pela denominação 'invasores', os militantes sem-teto que ousaram desafiar a estrutura fundiária especuladora e conservadora da cidade de Goiânia sofreram uma sequência de desqualificações por parte da imprensa local", fato também constatado por nós. Basicamente essa desqualificação ocorreu à medida que a ocupação ganhava força e foi maior no fim do ano de 2004 e início de 2005. Constatamos quatro grandes matérias do Jornal O Popular, no período de novembro de 2004, quando a ocupação se consolidou, denunciando a venda irregular de lotes e a existência de "laranjas", isto é, indivíduos atuando como "testas de 
ferro" ao emprestar seu nome para aquisição de lotes atendendo interesses de terceiros na ocupação.

O "filtro" do jornal pormenorizou, porém, o estado de abandono do imóvel que há anos estava entregue à especulação imobiliária, sem ocupar sua função social e sem pagar impostos ao Estado:

A Polícia Civil de Goiás vai instaurar inquérito para investigar a denúncia de venda de lotes na invasão do Parque Oeste Industrial, ocupada por famílias sem-teto em maio deste ano. A nvestigação será feita a pedido do Ministério Público estadual. m reportagem exclusiva publicada no domingo, O POPULAR mostrou a tentativa de negociação para compra de dois lotes O local, num total de 400 metros quadrados, por R $\$ 10$ mi. requisitou do jornal cópia da fita cassete em que está gravado diálogo por telefone com um dos posseiros que ocupam a área e também com uma pessoa que se identifica como um dos líderes da invasão Na gravação, o jornal tenta fechar o negócio, iniciado um dia antes, para compra de duas áreas na primeir etapa da ocupação. O terreno invadido engloba três áreas. "As denúncias são graves. "Se confirmadas, estas pessoas podem ser processadas por estelionato, porque vender coisa alheia crime", explica Maurício Nardini. Os proprietários do imóvel, que devem cerca de $R \$ 1,7$ milhão em impostos ao Município, formalizaram na semana passada uma proposta pela qual parte área seria dada em pagamento da dívida. (O POPULAR, 23 de novembro de $2004^{6}$

A caracterização do movimento também pode ser constatada pela escolha dos termos usados nas matérias: de todas as notícias analisadas constam os termos "invasores", "posseiros", "ocupação irregular" e "oportunistas". O enfoque é menos generalista com o movimento somente após a desocupação da área, quando milhares de famílias miseráveis não tinham para onde ir. Ainda assim, o enfoque das reportagens que visava criminalizar o movimento não desapareceu totalmente:

E apenas a esperança que ainda dá forças para as centenas de famílias miseráveis que, junto com outros de melhor poder quisitivo e oportunistas, foram despejados da maior e mais con Capuava e Novo Horizonte, dormindo em colchões emprestados, vestindo e comendo o que lhes é doado, abafados pelo calor do teto de Zinco (CZEPAK, O POPULAR, 20 de fevereiro de 2005, grifo nosso)

Já o Jornal Diário da Manhã mostra inicialmente uma cobertura oposta à de seu concorrente. O veículo foi o único a penetrar no dia-a-dia do local e rela6 Reportagem de Jornal sem autoria do repórter intitulada INQUÉRITO vai investigar denuncia de venda de
lotes. O Popular, Goiânia, 23 nov. 2014 tar o cotidiano dos moradores, que em nenhum momento são relatados como criminosos, conforme matéria "Com Cara de Bairro", cujo trecho segue abaixo:

Com oito meses de existência, a ocupação do Parque or dustrial (região sudoeste II) vem sendo organizada na tentativa de que a área seja desapropriada e regulamentada, assim como desejam os ocupantes. Desde que o terreno foi ocupado, os posseiros demonstram preocupação e cuidado com questões técnicas urbanísticas, no intuito de oferecer ao local ares de bairro. De certa forma, têm conseguido isso. Amanhã começa desocupação da área por ordem judicial, e há promessas de manifestação pacífica contra a ação por parte dos ocupantes. De maneira ordenada, criou-se um projeto de parcelamento da área. Um técnico em topografia foi contratado pelos próprios posseiros e, por meio de coordenadas de localização por satélite, lotes e ruas foram delimitados. Cada terreno mede cerca de $200 \mathrm{~m}^{2}$, o que condiz com as determinaçoes da legislaçăo federal de parcelamento de solo (Lei 6.766); as ruas foram abertas com nove metros de largura e, mesmo náo sendo asfaltadas, apresentam boas condiçoes para trafego. A ocupaçáo for dividida em trés etapas, que têm seus trução de creche, escola e sed para associação de mosadons. truçá de creche, escolla esede para associaçăo de moradores. O nome - Desgostosos por ver a áran onde mararm ser chamada de

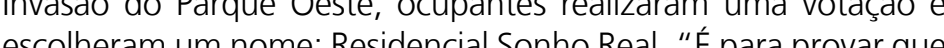
tudo com que sonhamos é possivel", explica o membro do conselho de Luta Pró-Moradia (criada dentro da o muparao), Américo Rodrigues. Hoje, o Sonho Real tem todas as suas ruas nomeadas, com números de quadra e lote para cada residência Na faltas, placas, vale escrever 0 endereço com tinta nos muros e paredes das casas. Ruas das Rosas, das Orquídeas, dos Cravos e a via mais movimentada da Rosaç̃̃o: a Avenida das Magnólias (CALICA DIÁRIO DA MANHÃ, 11 de janeiro de 2005).

Nota-se, claramente, o enfoque na questão do direito à moradia e capacidade de organização dos ocupantes. Diferentemente de O Popular, o Diário da Manhã mostrou uma abordagem mais humanizada dos ocupantes da área do Parque Oeste Industrial, inclusive com a publicação de artigos que questionam a decisão do judiciário e das autoridades de desocupar a área, frente ao gasto dos moradores. Porém a linha adotada pelo jornal no período próximo à desocupação se altera e também mostra suspeição sobre a lisura do líder do movimento e bem como sobre o suposto caráter violento dos ocupantes da área ao afirmar na data da desocupação que "dos 23 líderes da invasão, apenas um foi preso na área; o principal deles, Américo Rodrigues, estava escondido fora do Sonho Real e não deu nenhum apoio às famílias" (SABINO, DIÁRIO DA MANHÃ, 17 de fevereiro de 2005).

Essa mudança na postura do jornal pode ser explicada pelo fato de que o fazer jornalístico sofre, com frequência, influência diante de questões sociais especificas, como a necessidade de relatar corretamente o cotidiano das 
pessoas, ao mesmo tempo em que se revelam as dificuldades da imprensa em cumprir sua função social e política já que depende do mercado e do poder político para sobreviver. Num quadro, intitulado Perfil, apresentado no dia 04 de fevereiro de 2005, a publicação destacou o "perfil" dos líderes da ocupação, apontando os supostos bens de cada um (linhas telefônicas, veículos automotores e empresas) e os delitos penais que respondiam. Entretanto, 0 jornal não informou a fonte das informações lançadas (DIAS, 2007, p. 134).

Tudo isto indica que os dois veículos impressos priorizam o poder constituído como fonte de suas coberturas, caracterizando o movimento social por trás da ocupação da área de forma negativa e validando por meio de fontes oficiais um discurso que privilegia a desocupação da área como a melhor alternativa. Porém, o fato de os jornais O Popular e Diário da Manhã terem, no início, opiniões diversas sobre a mesma temática, mostra como essa caracterização do movimento é frágil e inconsistente.

\subsection{A posse e a situação legal do terreno}

Em relação à posse, ao direito à propriedade e à situação de imposto atrasados da área do Parque Oeste Industrial foi relegada ao segundo plano pela cobertura midiática, notadamente, com a aproximação do desfecho que resultou na desocupação. Acreditamos que este foi o grande embate a que fo submetido à sociedade goianiense: optar pelo cumprimento à risca do Direito à Propriedade, mesmo com um imóvel que não cumpria a sua função social, ou garantir o preceito constitucional do Direito à Moradia. De fato, este suposto antagonismo já foi resolvido pela própria Constituição Federal, em seu artigo $5^{\circ}$, inciso XXII, que estabelece "é garantido o direito de propriedade" e, logo mais, "a propriedade atenderá a sua função social". Já na parte dos "princípios gerais da atividade econômica", define que

"A ordem econômica, fundada na valorização do trabalho humano e na livre iniciativa, tem por fim assegurar a todos existência digna, conforme os ditames da justiça social, observados os seguintes princípios:

- soberania nacional

- propriedade privad

- função social da propriedade" (CONSTITUIÇÃO FEDERAL, 988)

Este fato apareceu de forma apenas tangencial no debate público. $O$ jornal O Popular pormenorizou a situação irregular do terreno nas suas reportagens e, quando mencionou o fato, o fez de forma sutil. Também deu considerável espaço para os advogados dos donos do imóvel se justificarem, sem esboçar nenhuma crítica ou contestação às condições por eles impostas para uma possível negociação, quando o desfecho do caso ainda estava longe de ocorrer:

\section{Os proprietários das três áreas ocupadas pelas famílias no Par-
que Oeste Industrial condicionam o fechamento do acordo com o Municíio à desocupação do imóvel. Liminar de reintegração de posse foi concedida pela juíza da $10^{a}$ Vara Cível de Goiânia, Grace Corrêa Pereira, em setembro. Diante do não-cumprimen- to da ordem de desocupação da área, a juíza encaminhou ofício to da ordem de desocupação da área, a juíza encaminhou ofício Jônathas silva, determinando que a retirada das famílias tenha início na quinta-feira. (O POPULAR, 23 de novembro de 2004).}

Em outra matéria veiculada três dias depois, o jornal volta a mencionar a posição dos proprietários do imóvel e inclusive dá destaque à defesa deles quanto às dívidas que possuíam junto ao Poder Público e ao fato de eles se colocarem à disposição para auxiliar na remoção das famílias que ocupavam a área, identificados pelo jornal como "invasores"( O POPULAR, 26 de novembro de 2004).

Já o jornal Diário da Manhã foi o único a dar alguma relevância a este fato, apontando claramente a questão das dívidas do imóvel que estava, há anos, entregue à especulação imobiliária e com uma dívida de impostos junto à prefeitura de Goiânia no valor de R\$ 3 milhões. Em outra matéria, de 22 de janeiro de 2005, o veículo avança no debate sobre loteamentos irregulares na capital, onde existiriam 175 áreas de posse e que $15 \%$ da área do município seria de loteamentos irregulares (SABINO, DIÁRIO DA MANHÃ, 22 de janeiro de 2005).

Em matéria do dia 27 de janeiro de 2005, o Diário da Manhã relata em tom positivo que a prefeitura e o governo estadual manifestaram a intenção em desapropriar a área. $O$ veículo chega a publicar um editorial, no qual se lê: "o DM é a favor da propriedade. Mas é contra o banho de sangue que se transformaria a desocupação do terreno. Por isso, apoiou a luta dos moradores realmente necessitados" (DIÁRIO DA MANHÃ, 27 de janeiro de 2005) Lembramos aqui que o editorial expressa a voz do dono do jornal e é uma das ferramentas de persuasão mais contundentes do jornalismo.

Como já dissemos a linha editorial do Diário da Manhã mudou radicalmente com a decisão das autoridades de desocupar a área. Prova disso é um novo artigo de opinião do jornal, que dessa vez justifica a desocupação violenta com o cumprimento da lei e da justiça, posição totalmente oposta à que tivera o veículo meses antes, como já evidenciamos. Desta vez o jornal questiona "quem são os verdadeiros responsáveis pelas mortes destes moradores do Residencial Sonho Real? Precisa dizer que são essas lideranças que incitaram ao descumprimento da lei quando a Justiça se tornou inflexível?" (AESSE, DIÁRIO DA MANHÃ, 17 de fevereiro de 2005).

Assim, com base nas matérias veiculadas pelos dois jornais percebe-se que a questão da posse do terreno, que estava entregue à especulação imobiliária e em situação irregular com o município foi pormenorizada, sendo abordada, de forma menos enfática e até justificada no Jornal O Popular durante toda a cobertura jornalística do episódio. Já o Diário da Manhã abordou a questão de forma mais incisiva no início de sua cobertura, mas não abordou mais a temática 
quando ficou definido que os ocupantes seriam despejados, juntando-se a linha editorial do concorrente ao justificar a desocupação exatamente pela importância de se cumprir a lei e o instituto da propriedade privada.

3.30 processo de ocupação e da desocupação

Ao analisarmos a cobertura dos dois veículos sobre a ocupação do imó vel constatamos que o Jornal O Popular demonstrou uma orientação editoria claramente contrária aos Sem-Teto. A primeira matéria do jornal sobre o episódio ocorreu em maio de 2004, poucos dias depois do início da ocupação, que já contaria com três mil famílias em barracas de lona.

Inicialmente o enfoque de $O$ Popular era noticiar o crescimento acelerado da ocupação, que se consolidava, à margem da ação do poder público, por se tratar de uma área particular. Em matéria publicada em seguida o crescimento exponencial da ocupação é novamente relatado, mas a partir deste ponto as matérias do jornal enfatizam cada vez mais a decisão da Justiça e todo o processo jurídico que culminou com a exigência da reintegração de posse:

Casas, lotes, quadras e ruas. A invasão de quatro áreas particulares no Parque Oeste Industrial, na saída para Guapó, deixou de ser um acampamento de barracos de lona preta e assumiu características de bairro, até com nome definido pelos sem-teto: Setor Sonho Real. A estrutura no local deve dificultar qualquer iniciativa de desocupacão como reconhece a Polícia Militar (PM). Os advogados dos proprietários das áreas informaram que o prazo de 20 dias para a desocupação, que atende à determinação judicial, terminou ontem. A PM jã planeja a retirada das famílias e aguarda apenas o comunicado da Justiça (SASSINE, O POPULAR, 05 de outubro de 2004)

A partir deste ponto é possível constatar que é dado enfoque cada vez maior às supostas condutas irregulares do movimento, como em uma notícia que informa sobre uma morte que teria ocorrido na ocupação devido à disputa de lotes. No jornal é relatado que a ocupação "terminou na morte do jovem Alison Alves da Fonseca, de 23 anos e em ferimentos no pai dele, Anésio Alves da Fonseca, 48" (ARANTES, O POPULAR, 04 de novembro de 2004). Na mesma matéria são relatados mais dois casos de violência que ocorreram no local, porém, alguns dias depois, é dado enfoque na suposta venda de lotes, em matéria publicada no dia 23 de novembro de 2004, com o título "Inquérito vai investigar denúncia de venda de lote" ${ }^{\text {" }}$. Na ocasião, o próprio jornal alega ter realizado uma "investigação" e comprovado a venda de lotes e que cerca de 300 ocupantes da área possuíam imóveis em outros bairros da cidade, num universo de quase 15 mil pessoas. Nova matéria publicada no dia 26 de novembro pelo jornal noticiava que 22 pessoas foragidas do sistema prisional foram identificadas pela polícia na ocupação.

7 Reportagem de Jornal sem autoria intitulada INQUÉRITO vai investigar denuncia de venda de lotes. O
Popular, Goiânia, 23 nov. 2014
A partir deste momento começa a proliferar o número de matérias com objetivo de criminalizar o movimento, conforme também concorda Silva (2007):

Ampla cobertura também foi cedida para buscar legitimidade junto à opinião pública diante da iminente ação de desocupação. Inicialmente destacou-se a "radicalização dos sem teto", para depois mostrar o desejo dos mesmos pelo enfrentamento, como foi no dia 31 de janeiro de 2005 através do título "Invasores votam por resistência" (SILVA, 2007, p. 125).

Já em matéria publicada nas vésperas da desocupação a caracterização do movimento como violento e fortemente armado atinge seu ápice:

Os invasores prepararam uma verdadeira operação de guerra para resistir ao despejo. Eles cavaram fossos, instalaram cercas de arame, colocaram pneus nas entradas da invasão e improvisaram ámas artesanais, como pedaços de paus pontlagudos e coqueteís molotov. No acesso principal, pela Rua das Magnólias - como os posseiros chamam a via aberta na terra -, estava con$L A R, 02$ de fevereiro de 2005)

Já a desocupação do local ganhou destaque em matéria do jornal O Popular de 17 de fevereiro de 2005 com o título: "Como foi o fim da maior invasão de Goiás" de autoria dos jornalistas Marcos e Filho. Embora as matérias relatem os casos de excesso e violência pela polícia o tom empregado relata o sucesso da desocupação, que mobilizou 2,5 mil policiais, sendo assim considerada pelo jornal O Popular como "a maior operação policial do estado de Goiás" (MARCOS e FILHO, O POPULAR, 17 de fevereiro de 2005). Curiosamente, a rapidez da ação e o fato de as vítimas fatais serem apenas os Sem Teto mostra que a resistência armada do movimento estava longe de ser o que os jornais locais propalavam. No dia posterior à desocupação o jornal deu total prioridade ao fato, com pelo menos oito grandes matérias que relataram detalhadamente como foi a desocupação, a opinião da Polícia Militar sobre a operação, uma manifestação dos Sem Teto após a ação de despejo, a vinda do Secretário Nacional dos Direitos Humanos, para apurar os excessos na desocupação e também as centenas de prisões de participantes do movimento.

Já em outra matéria, também veiculada logo após a desocupação, o veículo parece tentar "balancear" a crítica ao movimento ao retratar o drama - mais do que visível, daí a impossibilidade de acobertamento, como se este não existisse - das famílias desabrigadas, mas o faz ainda buscando dar um ar humanizado à violenta ação policial:

Uma música tocada em uma gaita no barraco pobre da invasão do Parque Oeste Industrial foi um sinal de esperança para Maria de Fátima Rodrigues de Miranda, 51 anos. Em meio ao tumulto 
e pânico do despejo, que envolveu a maior operação policial do Estado, Maria de Fátima, que é hipertensa e diabética, não teve dia. "Implorei para autorizarem meu marido a voltar lá vezes ao dia. "Implorei para autorizarem meu marido a voltar lá. Estavan
cortando a energia e as ampolas têm de ficar na geladeira". A cortando a energia e as ampolas têm de ficar na geladeira". A
mulher conta que um coronel permitiu a entrada do marido sob mulher conta que um coronel permitiu a entrada do marido sob a guarda de dois soldados. "Quando entrou no barraco, o sodado viu a gaita sobre a mesa e pediu que meu marido tocasse. é um sinal de que os grandes também vão cair em si e perceber que precisamos de um teto. " É apenas a esperança que ainda dá forças para as centenas de famílias miseráveis que, junto com da forças para as centenas de famillas miseraveis que, junto com jados da maior e mais conflituosa invasão da história goiana. Hoje eles aguardam uma solução espalhados pelos ginásios de esportes dos Setores Capuava e Novo Horizonte, dormindo em colchões emprestados, vestindo e comendo o que lhes é doado abafados pelo calor do teto de zinco (CZEPAK, O POPULAR, 20 de fevereiro de 2005).

Sabidamente, os dramas pessoais têm forte apelo popular e grande influência na opinião das pessoas. Talvez, atento a isso, o jornal tenha optado por "humanizar" sua cobertura somente após a desocupação, pois seria certamente mais difícil conseguir respaldo popular para ação se as outras matérias do veículo mantivessem esse enfoque.

Em sua cobertura o Diário da Manhã, inicialmente, criticava qualque ação que resultasse na desocupação do terreno e no confronto policial, conforme também constatou Dias (2007 p. 130) ao mostrar que até o mesmo o editor de política do jornal escreve um artigo em que critica o então prefeito municipal e o judiciário e defende "a desapropriação da área e sua consequente doação para os atuais ocupantes. Outra medida, em sentido contrário, configuraria 'erro histórico". O Diário da Manhã também critica o legalismo da justiça goiana, indiferente ao lado social da questão e, no início dá amplo espaço ao movimento, o que também é constatado por Dias (2007, p. 132) que destaca que: "numa sequência de reportagens, todas no dia 13 de janeiro de 2005, sob os títulos "Se eu morrer está bom", 'Esperança de ter casa de alvenaria", "Ataque de muriçoca", "Hora de recomeçar" e "Cachorro de estimação é roubado no bairro", é abordado a vida de resistência e de dificuldades dos moradores da ocupação, como a do aposentado Sebastião Quaresma da Silva.

Entretanto, como já dissemos, o veículo impresso muda totalmente de posição, passando a criticar e a não mais ouvir representantes do movimento e passa a publicar matérias amplamente favoráveis à ação da polícia e do Estado, dando amplo espaço para o secretário de segurança pública. O jorna destaca a rapidez da operação e inclusive culpa os próprios Sem-Teto pelas mortes ao afirmar que se alguém morreu (como morreu), não foi porque quis, mas porque estava no local errado, na hora errada e por um motivo igualmente errado, isto é, sem amparo da legislação (SABINO, DIÁRIO DA MANHÃ, 17 de fevereiro de 2005). O veículo menciona as mortes que ocorreram durante a ação, mas responsabiliza os manifestantes pelo ocorrido e na principal matéria a única fonte ouvida sobre o processo é a da própria Polícia.

Em outra matéria o Diário da Manhã relata detalhes da atuação da Polícia na desocupação, sempre defendendo a ação policial, que evitou uma tragédia maior já que "equilíbrio e o preparo da Polícia Militar evitaram uma grande tragédia no Residencial Sonho Real na manhã de ontem, como anteciparam os líderes da ocupação. A eficiência e o treinamento da corporação garantiram a desocupação em uma manhã" (SABINO, DIÁRIO DA MANHÃ, 17 de fevereiro de 2005). Apenas uma matéria do jornal com o título "Abandonados à própria sorte" mencionou a prisão de centenas de manifestantes e o fato de que outros milhares não tinham para onde ir. Esta reportagem também cita o apoio ao movimento por lideranças da igreja e a vinda do Secretário Nacional de Direitos Humanos à Goiânia para avaliar a desocupação.

\section{Considerações Finais}

A análise das matérias veiculadas evidencia que, embora o processo de ocupação/desocupação do Parque Oeste tenha sido amplamente coberto pelos veículos de comunicação, o movimento Sem Teto teve suas opiniões e reivindicações pouco apresentadas. Ao contrário, em momentos diversos, foi alvo de uma caracterização negativa. Apenas quando se mostraram derrotados, desmobilizados, enfraquecidos e se transformarem num gritante problema social ao ocuparem ginásios e terrenos sem a menor infraestrutura, chamando atenção de organismos nacionais e internacionais, é que foram considerados de forma humanizada pela imprensa local. Mesmo a questão da posse da terra e sua função social que deveria centralizar a discussão foi apenas secundariamente enfocado. Isto é esperado, na medida em que os dois jornais goianos, financiados em sua maior parte pelo poder estadual e por grandes anunciantes, boa parte dele as da cadeia de construção civil, dificilmente poderiam ser espaços adequados para a expressão da cidadania dos moradores provisoriamente instalados no Parque Oeste Industrial.

O episódio da maior desocupação da história de Goiás foi um caso singular que expôs a grande dificuldade de acesso aos meios de comunicação e expressão pelas minorias. Constatamos a enorme desigualdade no processo de luta pela visibilidade do movimento dos moradores, inicialmente, divergentes à união da linha editorial. Assim perguntamos, em conformidade com Poster (2005), que ao abordar o exerć́cio da cidadania no mundo contemporâneo diz que a questão principal é procurar entender justamente como os meios de comunicação podem promover novas relaç̃̃es políticas e sujeitos políticos, desencadeando um novo tipo de cidadão. Para o autor, a principal questão que deve ser levantada é se, sem regulação, podem os novos meios de comunicação promover a construção de novas formas políticas não subservientes aos poderes. 
Dois preceitos constitucionais (que no caso Parque Oeste Industrial foram tratados de forma antagônica), quais sejam, o Direito à Propriedade e o Direito à Moradia podem ser cumpridos se o Estado e a sociedade se atentarem para um princípio básico: exigir que a terra cumpra a sua função social. Para tanto, será necessário que os gestores públicos tenham, de fato, um bem elaborado plano de desenvolvimento e de políticas públicas que consiga pensar a cidade considerando o ponto de vista dos grupos econômicos, mas, sobretudo, as necessidades habitacionais dos demais cidadãos envolvidos. A história de Goiânia é a história "não divulgada" de sua periferização. O caso Parque Oeste Industrial, possivelmente, seja o ápice desse processo de modo que não deve ser esquecido, mesmo com todo o esforço em contrário do empresariado, de parte da imprensa, do Judiciário e dos governantes locais.

\section{Referências}

AESSE, U. Quem matou os moradores? Diário da Manhãa, 17 de fevereiro de 2005.

ARANTES, O. C. Disputa por lote em invasão acaba em morte. O Popular, 04 de novembro de 2004. ASSIS, D; MARCOS, A. Porretes, barricada e coquetel molotov. O Popular, 02 de fevereiro de 2005.

BARDIN, L. Análise de conteúdo. Lisboa: Ediçōes 70, 1977.

BOGDAN, R., BIKLEN, S. Investigação qualitativa em educação. Uma introdução à teoria e aos métodos. Portugal: Porto Editora, 1994

CALICA, F. Com cara de bairro. Diário da Manhã. 11 de janeiro de 2005.

CARLOS, A. F. A. A Cidade. São Paulo: Contexto, 2013

CARVALHO, J. M. Cidadania no Brasil: o longo caminho. Rio de Janeiro: Civilização Brasileira, 2011.

CZEPAK, I. A dor dos dias seguintes. O Popular, 20 fevereiro 2005

DIAS, L. D., FREIRE, R. M. Entre a produção jornalistica e o Sonho Real: rotina produtiva e o vivido pela ocupação urbana. In MAIA, J. F.

GIL, A. C. Como elaborar projetos de pesquisa. São Paulo: Atlas S.A, 2010.

GOIÁs. Secretaria de Estado de Gestão e Planejamento. Dinâmica Populacional do Estado de Goiás - uma análise do Censo 2010 do IBGE. 2011

LIMA, Angelita Pereira de; BORGES, Rosana Maria Ribeiro. História da imprensa goiana: dos velhos tempos da colônia à modernidade mercadológica. In: Revista UFG, ano X, n5 / Dezembro. Goiânia: UFG, 2008.

LUCA, T. A. Direitos Sociais no Brasil. In: PINSKEY, J., PINSKEY, C. B. (ORG.). História da Cidadania. São Paulo: Contexto, p.469-494, 2013.

MARCOS, A.; FLLHO, M. F. Como foi o fim da maior desocupação da história de Goiás. O Popular, 17 de fevereiro de 2005

McCOMBS, M. E.; SHAW, D. L. A função do agendamento dos media,1972. In: TRAQUINA, N. O Poder do Jornalismo: análise e textos da teoria do agendamento. Coimbra: Minerva, 2000.

MOYSES, A.; BERNARDES, G. Segregação urbana e desigualdade social em Goiânia: estado, mercado imobiliário e dinâmica socioespacial. In: MOYSÉS, A: Cidade Segregação Urbana e Planejamento. Goiânia: Editora da

OLIVEIRA, A. F. A reprodução do espaço urbano de Goiânia: uma cidade para o capital. In: MOYSÉS, A. Cidade Segregação Urbana e Planejamento. Goiânia: Editora da UCG,. 2005.
MORAES, Lúcia Maria. A segregação planejada: Goiânia, Brasilia e Palmas. Goiânia: Editora da UCG. 2006. OLIVEIRA, A.F, MOYSES, A. Segregação e planejamento excludente: cidade informe e degradação ambiental em

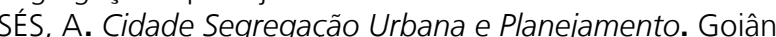

POSTER, M. Cidadania, mídia digital e globalização. In: MORAES, D. de (ORG.). Por uma outra comunicação: mídia, mundialização, cultura e poder. Rio de Janeiro: Editora Record, .2005.

SABINO, W. Comentário. Diário da Manhã, 22 de janeiro de 2005.

SABINO, W. O Sonho desmorona. Diário da Manhã. 17 fevereiro de 2005.

SASSINE, V. Invasão ja tem nome de bairro: PM planeja retirada das famílias, mas reconhece dificuldade em funçầo da estrutura existente no local. O Popular, 05 de outubro de 2004.

SILVA, M. L.. Segregação, opressão e resistência: a ocupação do Parque Oeste em Goiânia. Uma nova história de luta pelo Direito a Cidade. Braślila. UNB, Dissertação de mestrado. 2007. Disponível em http://repositorio.unb. br/handle/10482/2725. Acesso em fev, 2014.

RSh REVISTA SOCIAIS \& HUMANAS - VOL. 32 / No 3 - 2019 